\title{
The Use of Indigenous Materials in the Teaching and Learning of Geometry
}

\author{
Zingiswa Mybert Monica Jojo \\ University of South Africa, P.O. Box 392 Pretoria, South Africa \\ Telephone: +27 12429 6627, E-mail: jojozmm@unisa.ac.za
}

KEYWORDS Communication. Construction. Design. Indigenous Materials. Representations

\begin{abstract}
This paper reports on an exploration of grade nine learners' experiences in the design and construction of double-storey artefacts project at a secondary school in KwaZulu Natal, South Africa. The project engaged a process of drawing and construction of those artefacts in a technology education classroom to enhance and inform the teaching of geometry and to allow learners to both reflect and use the Geometry they know as a springboard for further study of Euclidean Geometry. This was qualitative study in which data was collected through observations of artefacts and semi-structured interviews with a purposefully selected sample of five learners. The analysis of data revealed that Geometry taught in a free environment allows learners to reflect and share their experiences for better understanding mathematics concepts.
\end{abstract}

\section{INTRODUCTION}

Mathematics may be defined as a human activity that involves observing, representing and investigating patterns and quantitative relationships in (i) a physical and social phenomena and (ii) between the mathematical objects themselves (DOE 2002). The ability to interpret, calculate, measure, estimate, compare and contrast, as well as visualise and represent object with confidence and accuracy are amongst the skills that the learners should acquire in the learning of mathematics. Bhagat and Chang (2015) in their study on the use of geogebra in geometry learning concluded that learners need a guide to explore and visualize mathematics, especially geometrical concepts. Hwang and $\mathrm{Hu}$ (2013) assert that learning geometry highlights the importance of exploring different representations such as virtual manipulative, written math formulas, and verbal explanations, which help in development of mathematical concepts and critical thinking. Geometry in particular, is about visual imagery that can be used by learners (Gattegno 1965). Learners should be encouraged to represent and describe what they see in their environment. Nonetheless, learners often find geometrical concepts abstract and difficult to

Address for correspondence:

Dr. Moshe M. Phoshoko

PO Box 392 Unisa

South Africa, 0003

Telephone: +27124296993

E-mail: phoshmm@unisa.ac.za understand (Bhagat and Chang 2015). Meanwhile Regents (2014) suggest that teachers should always look for opportunities of connecting mathematics with the real world by conceptualizing, analysing, interpreting, and validating conclusions in order to make decisions about situations in everyday life, society, or the workplace. In this way learners will be encouraged to represent and describe what they see in their environment. Duval (1995) acknowledges that Geometry involves three kinds of cognitive processes working together: (i) visualisation regarding space representation, (ii) construction using tools like rulers and pencils, and (iii) reasoning. According to this author, activities in Geometry teaching and learning should involve all three of the aforementioned processes even though they can occur apart from each other. Given the maximum hours of mathematics teaching of sixty minutes a day in the country, such activities of practical nature tend to be presented as projects for learners to do investigations. This was relevant to one of the aims of the National Curriculum Statement Grades R-12, to produce learners that are able to communicate effectively using visual, symbolic and/or language skills in various modes (DBE 2011).

Assuming that drawings and shape form the basis of Geometry, the Department of Basic Education requires grade nine learners to analyse, identify, classify and represent drawings in their study of mathematics. Mogari (2000) asserts that Geometry content would be more meaningful, if it could be taught in a practical and familiar con- 
text that motivates the learners. Anderson (1980) argues that teaching mathematics in a way detached from cultural aspects and in a purely abstract and symbolic way, is not only useless, but also very harmful to the learner, to society, to mathematics itself and to future generations. It is therefore a concern whether Geometry taught in mathematics classrooms is not restricting learners to proof whilst neglecting other aspects like drawings and designs. Thus a significant emerging question is the following: How can the teaching of Geometry allow the learners to both reflect and utilize what they already know as a starting point or springboard for further study of Geometry?

At present, Geometry education in South Africa is in a state of turmoil and a great number of learners perform poorly in it (Mogari 1998). This observation alone, suggests that there is a need to seek an alternative approach to the study of shape and space-related mathematics. Through design learners acquire skills, knowledge attitude and values that can be transferred and applied across the curriculum. In South Africa, the Department of Basic Education embarked in a process of trying to redress the imbalances of the past and the on-going challenges experienced as a result of the introduction and implementation of Outcomes Based Education. The Department then introduced the National Curriculum Statement for grades R to 12 (DBE 2011: 3).). The curricula have since been replaced by a comprehensive Curriculum and Assessment Policy Statement which was introduced to replace documents which were creating confusion for mathematics teachers and officials in the previous years.

The National Curriculum Statement era in South Africa tried to address a problem of poor performance in Geometry reflected in Mathematics Senior Certificate results from 2003 to 2008. This was done by pushing Geometry to a third paper written optionally by mathematics learners in matric during those years. Also most teachers did not teach Geometry at all since it was optional for examinations in grade 12 . Only 28 percent of matric learners wrote the Geometry paper in 2009 and of those 19.3 percent performed poorly (DBE 2010). These results imply that the country then suffers engineers with the knowledge of Geometry. Moreover, higher institutions were stressed with introduction of the foundation phase where the concepts that were not addressed in school mathematics were taught to aspiring engineers from scratch. This included Geometry. Curriculum Assessment Policy Statement has since reinstated the examination of Geometry in senior certificate from 2011 to date. This is now a huge problem for both teachers and learners again.

National Planning Commission further emphasises that, "The performance of South African learners in international standardised tests should be comparable to the performance of learners from countries at similar level of development and with similar levels of access" (National Development Plan 2030 (2012: 296)). At this point, South African learners in mathematics are still considered to be far below the international benchmarks. For South African learners to perform to the envisaged standards internationally there has to be an adequate level of accountability and support for the teachers. They need to be equipped with skills and strategies to use their indigenous knowledge and language to teach mathematics. Kobiela and Lehrer (2015) in their analysis of classroom interactions during 16 episodes spanning earlier and later phases of instruction illustrate how learner participation in aspects of definitional practice influenced their emerging conceptions of the geometry of shape and form. In their study (Kobiela and Lehrer 2015) identified (a) requesting learners to participate in various aspects of practice, (b) asking questions that serve to expand the mathematical system, (c) modeling participation in aspects of practice, (d) proposing examples that create contest and (e) explicitly stating expectations of and purposes for participating in the practice.as several forms of teacher discourse that support learners' participation in a geometry classroom.

Atebe and Schafer (2010) assert that once learners have attained an acceptable level of proficiency in the teaching language, then their conceptual or mathematical understanding will improve. Language is undoubtedly an essential tool in communication, and perhaps Geometry stresses the use of language more than any other part in mathematics.

On the other hand, the outcomes from the Trends in International Mathematics and Science Study (IEA 2011) revealed that there was evidence of many very low performing ninth grade mathematics students in at least three countries, with the percentage of students with 
achievement too low for estimation exceeding 25 percent in South Africa and Honduras and between 15 percent and 25 percent in Botswana. Also, the percentage of learners achieving more than 50 percent in mathematics in 2012 ranges from 0.5 to 5.0 across all provinces in South Africa (DBE 2012). This requires a change in the strategies used in the teaching of mathematics. This view is also emphasised by Kotze (2007: 21), who claims that teachers should be able to use teaching strategies that will enhance cognitive learning in mathematics.

\section{Research Questions and Focus of Inquiry}

The focus of this paper was to explore how the experiences that the learners go through in the Technology classroom during the construction and design of artefacts, can be used to inform the teaching of geometry in the mainstream mathematics classes. The research questions were: (i) How do the learners represent existing objects through geometric diagrams? (ii) Can the geometric manifestations tie up and be implemented in the mainstream mathematics classes? And (iii) What geometry was manifested in the finished artefacts?

\section{Literature Review}

Drawing serves as a powerful tool in the knowledge and understanding of geometric figures and the awareness of the links between Geometry and real world. Wilson (1977) states the ability to draw, sketch and use geometric instruments as one of the most important fundamentals in the teaching of Geometry. He further asserts that scale drawing provides an appropriate way of producing mathematical models that are accessible to all learners. This includes a wide range of practical situations like building plans, drawings of maps and others. However many learners perceive Geometry as a random collection of unorganized claims (Sarli 2015). In the particular study that is reported here, learners used scale drawing as they drew and constructed models of double-storey buildings in the project assigned to them. This skill was not taught to them prior to the constructions and drawings.

Alexandrov (1995) views Geometry as a union of logical imagination and practice. This belief informed the drawing and completion of con- structed artefacts in the reported study. Each geometric concept should be demonstrated and understood in material form as a reflection of reality and not only as drawings on paper or chalkboard. An informal practical approach to Geometry that is intuitive and experimental has to give the learners imagery and dynamics through the design and construction of artefacts. This involves learners talking to the teacher, sharing ideas amongst themselves and hence assimilating mathematics meaning through new concepts introduced to them in the classroom in a bi-directional manner. They have to be aware of the geometric experience and articulate it, and be able to apply this experience to appropriate situations. Such activities as those of designing and constructing models of artefacts encourage learners to develop and explore their creativity and to exercise their spatial sense. Specific learning strategies and styles are rarely illustrated or prescribed by the teacher. Learners demonstrate their own abilities of interacting with new knowledge. The learning process should therefore not be structured to lead to a set of procedures or methods that the teacher approves of. Rather, learners must invent their own ways of doing mathematics and must be free to choose learning strategies that suit them. Such an opportunity was provided for the learners in this study.

The world trend in education towards the recognition of the learners, their experiences including language of communication in the classroom, is a major concern that affects the teaching of mathematics (Adler 1991). The accommodation of second language speakers would allow a different classroom culture in which both the teacher and learner are active participants and meaning-makers in the teaching and learning process. Steffe (1990), and Confrey (1990) emphasise communication and negotiation and hence the use of language in the construction of meaning. They further advocate that communication through discussions with others is important for construction and reconstruction of concepts. This implies that in a mathematics classroom, learners must have some form of verbal interaction in order to share their meaning of mathematical concepts. Concepts are introduced in mathematical language, for example a point that sometimes is interpreted as 'a dot', whilst the meaning of 'position' might give a more clear meaning to learners. Also the diagrams and properties of various quadrilaterals with some char- 
acteristics may be seen as something different from what the learners already know. During the execution of this project, there was no intentional control over the language to be used, and no particular sequence was prescribed in which constructions and designs had to be done. The learner decided from the available resources, and used his/her interpretations to produce the desired end product. These activities were centred on the necessity for exchange of information, which in turn facilitated participation in their world of experience.

Sugiarto et al. (2012) claim that creative thinking abilities in Geometry can be fostered by instruction in class that involves use of attractive, iconic, symbolic, and practical learning tools when teaching. That study aimed at making the syntactical and rhetorical structure of mathematical language, a clear and explicit tool of teaching used to increase the learners' understanding of geometric concepts. The idea that Geometry goes beyond the symbol manipulation and solving of equations was taken as basic. Geometry concerned with understanding the interrelationships amongst patterns and focuses on proof and argument with an emphasis on clear and concise expression of ideas. This therefore requires the learners to have developed a logical and rhetorical structure where they are exposed to mathematical thinking. The exercise design and construction of artefacts is an active process of meaning making where emphasis is not only on instruction but on creations that learners can come up with.

\section{Theoretical Framework}

This study drew from the (i) constructivists views by von Glasersfeld (1984), Cobb (1994), Confrey (1990) and Steffe (1992); (ii) the work by van Hiele's (Piaget 1966) on Geometry teaching and learning; and (iii) Piaget's theory on mental representation of space. Social theories refute learning without participation, and consistently perceive knowledge as a learner's action upon an object. The abstractions made are constructed by the learner who consequently discovers the properties of the object from both the action and what the learner already knows. Learning starts at a physical level where the learner does some action which then develops to an internalization process. Learners are assumed to construct their mathematical conceptual understand- ings as they participate in cultural practices and whilst interacting with each other. Nickerson (1988) associates this with inquiry based learning which he defines as including (i) constructivism, (ii) conceptual understanding rather than procedural efficiency, (iii) responsiveness to what students already know, and (iv) connections to the world outside of schools.

Piaget (1966) advocates that, learners build their mental representation of their world through progressively reorganising prior active manipulation of an environment. This implies that relations, such as connectedness, enclosure, and continuity, are constructed through imagination followed by projections and use of Euclidean Geometry. This follows from the Piagetian work that presented two major themes: (i) our mental representation of space is not a perceptual figuring out of what is around us, and (ii) the progressive organisation of geometric ideas follows a definite order, which is more experiential and mathematically logical than historical. Conceptual knowledge can therefore not be transferred from one person to another, but must be actively built up by every learner based on personal experience. The teacher in the reported study was not thought of as a dispenser of knowledge, but a facilitator of a classroom culture for learners to be involved in sharing, evaluating, negotiating, exploring and socially interacting with each other. Indeed in this study, learners shared ideas, explored various options during the design process using indigenous materials and eventually presented a new product using geometric representations of space and material at their disposal.

Van Hieles (1986) asserts that the teachers need to assign learners with activities that permit them to explore, talk about and interact with content at the next level, while increasing their experiences to have the best chance of advancing to the next level of thought. Teaching certain techniques in certain ways allow students to learn Geometry by means of hands-on activities. In so doing, students can combine their experiences with problem-solving strategies and reach the higher order thinking skills at an abstract level (Fuyset al. 1988). In the reported study, the stages outlined in van Hiele (1986) and reworked by Clements and Battista (1992) were considered. Learners first gathered information through discussion, and then explored the objects of instruction in structured tasks 
without guided orientation; it followed a description of what the learners had learnt in explication, and free orientation was provided for them to apply and investigate open-ended tasks, along with the development of a new network of objects and relations. Through this approach the learners were afforded a chance to communicate their wishful thinking through drawings of double-storey houses (izitezi) that they always envy to live in, should they migrate from their rural land settings. Part of the design experiment in the classroom was outlining the work plan in Table 1 which was followed by the learners to carry out the given task.

\section{METHODOLOGY}

The study was qualitative, in nature and in relation to the types of data. Main data was collected through semi-structured interviews of a sample of five grade nine learners from a population of forty-eight learners in the classroom. Learners were observed and interviewed at different intervals of their designs whilst they drew the figures and constructed their artefacts representing double-storey buildings (izitezi) as commonly known to them. Five learners were selected on the basis of the drawings and designs made and interviewed using open-ended questions to extract the procedures for in the drawings. The observations were recorded in the form of notes on every activity done by the learners, with interactions between them and both the drawing and construction practice. Data was analysed to extract information on measurements, comparisons, estimations, scaling, and symmetries manifested in the learners' drawings and the artefacts constructed. There were three specific progressive research questions framing the analytical actions:

- What kind of geometric representations of finished artefacts are the learners able to draw without prior instruction?
- How do learners represent existing objects through geometric diagrams?

- What Geometry is manifested in the finished artefacts that the learners construct?

In addressing the research questions, four assertions discussed below were made and constitute the main results. In order to come to the results, an interpretive method which sought to develop an in depth analysis and description of what transpired during the design and construction of double-storey artefacts in the mathematics classroom was used. In the technology classroom learners were observed on how they started their drawings, what figures they used as the first shape on which the whole drawing would be projected, the explanations given through interviews conducted with the learners and discussions, interactions and language used amongst them. During the construction stage, measurements cut from the available material, comparisons of cut strips of card box and the shapes they represented in Geometry, how these were pasted and connected to make a complete artefact were of importance to provide an in depth analysis of what transpired in this study.

\section{OBSERVATIONS AND DISCUSSION}

The results are discussed based on four assertions coming from the analysis of what was made during the different processes of construction. The observations in the design and construction of the learners' artefacts bring up evidences of (i) the use of Geometry, (ii) the reflection and explanations in various steps of the process, (iii) the use of particular geometric shapes, and (iv) the strategies in the drawings.

Assertion 1. Learners used geometric representations and projections in their drawings of their own choice

Table 1: Work plan in the design and construction of artefacts

\begin{tabular}{ll}
\hline Task & Description \\
\hline $\begin{array}{l}\text { Design brief } \\
\text { Artefact brief }\end{array}$ & $\begin{array}{l}\text { Draw on an A4 size paper a double-storey house or flat that you have seen } \\
\text { Make a model of the double-storey represented in your design brief }\end{array}$ \\
$\begin{array}{l}\text { Materials to be used } \\
\text { Artefacts must be neat, accurate and proportional }\end{array}$ \\
$\begin{array}{l}\text { Pieces of cardboard, glue, cello tape, rulers, pairs of scissors, pritt, glass } \\
\text { paper, pencils, strings, measuring tape, pins and needles etc. } \\
\text { Shape of the model } \\
\text { Cost }\end{array}$ \\
$\begin{array}{l}\text { To be decided by the learner, not very small nor very big } \\
\text { To represent the drawing in the design brief } \\
\text { Minimal, with the teacher and learners bringing all material from home }\end{array}$
\end{tabular}


Questions concerning the potential significance about where to start the drawing or the involvement of any measurement whilst drawing were posed to the learners to find out the knowledge of geometric representations in their drawings. Three out of the five learners started their drawings with two parallelograms for the gable roof while the other two learners started drawing with garages at the bottom and worked their way up the double-storey house. It was observed that each learner had a particular shape in mind of the double-storey house that was being drawn. A combination of geometric structures like parallelograms, trapezia, triangles, rectangles, squares, pentagons and some curved garage representations were observed. Some learners used measurements to elucidate important features of their roofs. Here is an example of a learner's explanation:

When I draw the gable part of the roof, I measured so as to make sure that both lines on either side are equal.

Learners displayed knowledge of congruency, parallelism, estimations, similarity and perspective drawing as geometric representations used without prior formal instruction. In their own non-academic language they convinced each other justifying isometrics, and projections made in their finished artefacts. This is in line with Hwang and $\mathrm{Hu}$ (2013) who highlighted the significance of using verbal explanations, to explore different representations and as such enhance learner's development of mathematical concepts and critical thinking. It was interesting to listen to their explanations enabling other learners' awareness of shapes combined to form finished artefacts.

Assertion 2. Learners did not use scale drawing or preserve lengths when representing existing objects through diagrams, but when designing and constructing modelsartefact.

The essence of the drawing exercise was to get answers to questions about how the drawing was done, why it was done like that, where the idea came from, and how the drawing was started and why. Although three of the learners used no particular measurements in their drawings, they indicated that the measurements of the other parts of the house depended on the roof or garage already drawn. To explain this, one of the learners said:

No I did not measure the lines when I started, but when I saw the gable part of the roof, I measures the lines to make sure that they are equal ziqhubekekahlekuzeindluingatyeki (projected nicely, otherwise my house would be skewed).

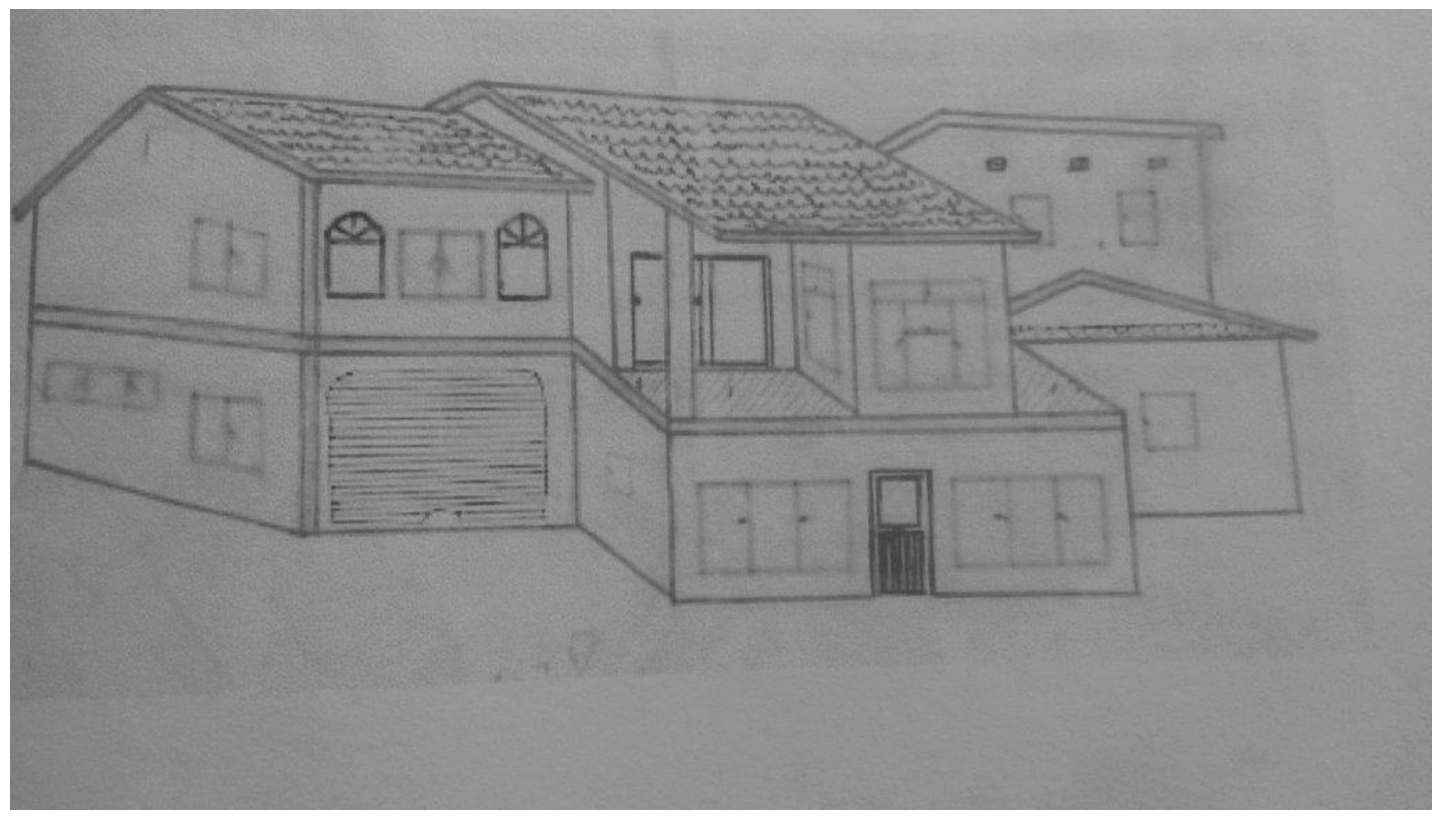

Fig. 1. Drawing of an artefact 
All five learners were able to represent the actual artefact with external features on the size paper. The idea of which house to represent depended mostly on houses that some of them saw and admired in the nearby town. One such house is displayed in Figure 1 as drawn by one of the learners. The drawing was good but the learner struggled to preserve length while using available material to form an artefact. This drawing shows that it is easier for the learner to draw an existing artefact than to create one from a given drawing. Language as a necessary tool for communication has been used for the construction and negotiation of shared meanings that lead to mathematical knowledge (see Adler 2001; Moschkovich 2007; Planas and Civil 2012).

Assertion 3. Learners used measurements based on a chosen scale to produce finished double-storey model houses which revealed the use of Geometry.

This information was sought to respond to the research question, 'What geometry is manifest in the finished artefacts? Observations at the different orientations of the diagrams, some parts of their drawings were shaded to bring out the perspective as clearly as is possible. This often included witnessing the learner trying to visualize and orient a model in the same way as the diagram on paper. This certified the fact that, as opposed to Algebra, which is more methodological and structured, Geometry is more spatial, visual and insightful (Wilson 1977).

Learners used scale drawing, perspective drawing, isometric and orthographic projections without knowing the formal definitions of the concepts. Wilson (1977) further avers that anyone who makes objects to her/his own designs comes in time to have a feeling for shapes and sizes, and this is an indispensable part of geometric education. Indeed from this study it can be revealed that Geometry is very close to the natural senses of the learner and also so close to the level of awareness such that the learners do not think of it as Geometry. Moreover, Kobiela and Lehrer (2015) in their framework of definitional practice cite mathematical practices that reinforce examples that create contest to enhance and evoke the learners' natural geometric perceptions.

The learners showed evidence of recognition of the proportionality of space to be used as they cut out windows and doors into the skeleton of walls in their buildings. In most instances, like the measurement of the roof of the model house, learners used estimated measurements.
The explanation was that the roof had to project over the front walls so that it could be steep enough to cater for rainy days. They used appropriate scale though and in their adjustments, length was preserved of all the cardboard measures they had to cut.

Assertion 4. The geometric manifestations in the drawings and finished artefacts were evident.

Learners used arguments in their explanations that revealed knowledge of Geometry. They used mathematical conventions, rules and techniques to build arguments that could not be refuted, in explaining why they constructed and drew diagrams the way they did. One learner said,

I had to divide the floor into four equal parts, place each part on top of each other, then cut out windows such that they are equal in all respect.'

This is congruency. The expansion by means of adjusting the scale of the drawing to three times that of the artefact was a form of size change used by learners without effort. Learners used proportional contractions to represent the actual double-storey houses on size papers. In the size change process, shape is preserved, the preimage of the house and image were similar. Similarity covers comparison of triangles, quadrilaterals and circles in the grade nine learning scope. At this stage the fact that similar triangles are equiangular is still underemphasized. This attribute was clearly revealed in the learners' drawings.

The activities in which the learners were engaged in during the course of this study involved a combination of cultural aspects using indigenous material and an allowance of learners to work in classroom environment freely allowing learners to apply their insights and experiences. Geometric properties like effective scale reduction and expansion were accurately and properly combined and revealed how delighted each learner was in making his/her own model. This has also been recommended by some scholars (Kaino 2013) as a way to bridge the gap between what is taught in school and what happens in the environments in which the learners live.

\section{CONCLUSION}

Visual perception depends on transformations in one's mind since the variety of retinal images derived from any object seen at different angles at different times have to be linked in the 
mind if recognition must take place. Also imagination is a personal world in which these transformation rules are unchallenged. Thus, a bridge exists between what the teacher knows, what the learners can do and some of the mathematics the teachers would like them to learn. The idea of transformation in the mind becomes a tool that a teacher can use, a tool that does not dehumanise learning because it corresponds to one aspect of the voluntary activities of the child.

This has been evident in this study as learners gathered information on how they could build the double-storey house and what material was available for use in the process. They accessed information regarding the size of the artefact, recorded measurements and predicted the different walls to be constructed before the others were done. They identified the congruent faces of the building, compared similar sides and used scale drawing to represent their creativity in the form of drawings. Management of scarce resources, knowledge and skills related to graphics, for example, use of colour, rendering techniques, two and three dimensional drawings, planning, sketching, drawing, calculations and construction of models were done by learners on their own. Furthermore they justified the choices made in each stage of the drawings and constructions. This is Geometry enriching reasoning skills.

\section{RECOMMENDATIONS}

This paper further recommends that other content learning areas could be used to enhance appreciated and the learners' attitudes towards geometry using the development and mathematical skills displayed. Learners should be allowed to use any language to communicate mathematical ideas, concepts, generalizations and thought processes. This will include the use of language to express mathematical observations, interpretation and analysis of models. Most profoundly learners it should be afforded an opportunity to actually do mathematics based on ethno mathematics, construct objects and comment on their presentations. It can be concluded that learners should be regarded as intelligent and creative individuals whose questions are valued. Teachers should therefore afford the learners more choice in discussion. This would give the learners effective decision making powers in Geometry.

\section{LIMITATIONS}

The paper reports on a small scale study in which a small sample was used in order to enhance the richness of qualitative data. Thus, the results cannot be generalised to apply to all grade nine learners. However the processes followed in this study can be utilised to adapt learners to classroom environments that allow them responsibility for making sense of what is being learnt.

\section{FOR FUTURE STUDIES}

Learners need a platform to reflect, refine, generalise, ask questions and make claims to convince themselves of the choices made to acquire knowledge in a learning activity. One of the implications for mathematics teaching is that teachers need to provide opportunities for learners to struggle with the problem of communicating their diverse personal intuitive mathematical thoughts. The outcome of this exercise would be learner's own construction of notations, definitions, proofs and the appreciation of Geometry as a whole. Lessons should be conducted in a manner that enables the learners to proceed from their intuitions to develop the ideas required by the learning area. In this way the information learnt will be at the disposal of the learner, he/ she owns it and can process and use it in ways that he/she chooses.

\section{REFERENCES}

Adler J 1997.Teaching Cases and Dilemma Language: A Potentially Powerful Tool in Mathematics Teacher Education. Proceedings of the $5^{\text {th }}$ Annual Meeting of SAARMSTE City, State: Publisher, pp.197-203.

Alexandrov AD 1995. Geometry as an Element of Culture: Selected Lectures. ICME, Russia; St Petersburg Department of the Steklov Mathematical Institute.

Anderson D 1980. For the Learning of Mathematics. Short Communication presented at the Fourth International Congress on Mathematics Education, August, California: FLM Public Association.

Atebe HU, Schafer M 2010.Terminology primacy in high school learners' geometric conceptualization. In: V Mudaly (Ed.): Proceedings of the $18^{\text {th }}$ Annual Conference of SAARMSTE. Volume 1. City, State: Publisher, pp. 119-129.

Bhagat KK, Chang CY 2015. Incorporating GeoGebra into Geometry learning-A lesson from India. Eurasia Journal of Mathematics, Science and Technology Education, 11(1): 77-86.

Clements DH, Battista MT 1992. Geometry and spatial reasoning. In: IDA Grouws (Ed.): Handbook of Research on Mathematics Teaching and Learning. New York: Macmillan/NCTM, pp. 420-436. 
Cobb P 1994. Where is the mind? Constructivist and socio-cultural perspective in mathematical development. Educational Researcher, 23(7): 13-20.

Confrey J 1990. A review of research on student conceptions in Mathematics and Science and programming. In: CB Casden (Ed.): Review of Research in Education, 16: 3-55.

Department of Basic Education 2011. Government Gazette, 555: 34600

Department of Education 2002. Revised National Curriculum Statement Grade 9.

Duval R 1995. Why teach Geometry? In: Perspectives for the Teaching of Geometry for the $21^{\text {st }}$ Century. Department of Mathematics. Carmelo Mammana: University of Catania.

Fuys D, Geddes D, Tischler R 1988. The van Hiele model of thinking in geometry among adolescents. Journal for Research in Mathematics Education, Monograph 3, Reston, VA: NCTM, pp 1-2.

Gattegno C 1965. Mathematics and Imagery.In: Mathematics Teaching 33. UK, Derby: Association of Teachers of Mathematics.

HwangW-Y, Hu SS 2013. Analysis of peer learning behaviors using multiple representations in virtual reality and their impacts on geometry problem solving. Computers and Education, 62(0): 308-319. doi: http://dx.doi.org/10.1016/j.compedu. 2012. 10. 005

International Association for the Evaluation of Educational Achievement 2011. TIMMS 2001. International Results in Mathematics. Chestnut Hill, MA: IEA.

Kaino LM 2013 Traditional knowledge in curricula designs: Embracing indigenous mathematics in classroom instruction. Studies in Tribes and Tribals, 11(1): 83-88.

Kobiela M, Lehrer R 2015. The co-development of mathematical concepts and the practice of defining. Journal for Research in Mathematics Education, 46(4): 46(4): 8-12.

Kortze G2007. Investigating shape and space in mathematics: A case study. South African Journal of Education, 27(1): 19-35.
Luthuli DV 1996. Geometric riders and proof. Pythagoras. Centrahill: Amesa.

Mogari D 1998. Geometrical constructs and pupil's construction of miniature wire cars, Pythagoras, 46/ 47. Centrahill: Amesa.

Mogari D 2000. Problems associated with the use of ethnomathematics approach. In: S Mahlomaholo, M Nkoane, K Smit-(Eds.): Proceedings of the $8^{\text {th }}$ Annual Conference of the Southern African Association for Research in Mathematics and Science Education. South Africa: University of Port Elizabeth.

National Development Plan 2012. National Planning Commission: The Presidency, Republic of South Africa.

Nickerson RS 1988. Technology in education in 2020: Thinking about the non-distant future. In: RS Nickerson, PP Zodhiates (Eds.): Technology in Education: Looking Toward 2020. Hillsdale, NJ: Erlbaum, pp. 1-9.

Piaget J 1966. Psychology of Intelligence. Totowa, New Jersey: Littlefield, Adams and Co., 119-155. In: AN Boling 1991. They don't like math? Well, let's do something! Arithmetic Teacher, 38(7): 17-19.

Regents Examination 2014. Geometry Sample Items. Orlando, FL: Academic Press.

Steffe P 1990. Prospective for alternative epistemologies in education. In: LP Steffe (Ed.): Constructivism in Education. Hillsdale, N.J.: Lawrence Erlbaum Associates, pp. 41-56.

SugiartoI, Junaedi ST, Waluya B 2012. Pembelajaran Geometri Berbasis Enaktif, Ikonik, Simbolik Untuk Menumbuhkan Kemampuan Berpikir Kreatifpeserta Didik Sekolah Dasar. Journal of Primary Educational, 1(1): 23-29.

Van Hiele PM 1986. Structure and Insight: A Theory of Mathematics Education. Orlando, FL: Academic Press.

Von Glasersfeld E 1984. An introduction to radical constructivism. In: P Watzlawick (Ed): The Invented Reality. New York: Norton, pp. 17-40.

Wilson WW 1977. The Mathematics curriculum London, UK: Blackie and Son Ltd. 